\title{
Cura, Memória E POLÍTICA EM MoÇAMBIQUe
}

SANTANA, Jacimara Souza. Médicas-sacerdotisas: religiosidades ancestrais e contestação ao sul de Moçambique (c. 1927-1988). Campinas: Editora da Unicamp, 2018. 383p.

As contestações anticoloniais das populações rurais africanas, por vezes categorizadas como "pré" ou "protonacionalistas", foram postas numa relação de hierarquia evolutiva com aquelas protagonizadas por frentes e partidos políticos orientados por ideologias “modernas”. A oposição tradicional versus moderno, organizada como teleologia, que deduz a superação linear da modernidade sobre a tradição, tem sido felizmente repensada. Os próprios termos utilizados, oriundos de uma visão modernista, têm sido ressignificados, sugerindo uma dinâmica muito mais complexa entre continuidade e mudança. As contestações rurais, informadas por cosmologias próprias e, via de regra, associadas a uma linguagem religiosa, passaram a ser vistas, a partir de então, menos como fenômenos conservadores e mais em toda a sua complexidade criativa.

O livro de Jacimara Souza Santana combina de forma interessante a abordagem historiográfica e a interpretação antropológica, ao aproximar-se da atuação dos tinyanga (plural de nyanga), chamados durante o regime colonial, pejorativamente, de curandeiros ou feiticeiros. O livro também aborda a hostilidade a este grupo pelo Estado revolucionário comandado pela Frelimo, até 1988. A partir daí a relação dos tinyanga com o Estado conhece uma fase de aproximação cheia de ambiguidades, até a criação da Associação dos Médicos Tradicionais de 
Moçambique (Ametramo), em 1992, ao final da guerra civil, quando se abre um novo período nas relações entre os dois lados dessa equação.

A autora realizou trabalho de campo e pesquisa de fontes em Moçambique, como também em Portugal, além de um período de pesquisas no México. Aprendeu suaíle como estratégia para aproximar-se da língua changana, largamente utilizada pelo grupo com o qual conviveu em 2012, na província de Gaza e na capital do país, Maputo. O diálogo produtivo com a Antropologia não é resultado apenas da recolha de história oral através de entrevistas conduzidas durante sua estadia em Moçambique, mas sobretudo do uso das interpretações, advindas do debate antropológico, sobre temas como a mobilização político-religiosa, as cosmologias que informam compreensões distintas sobre corpo, saúde e equilíbrio social, a relação entre "feitiçaria" e modernidade.

A perspectiva bem informada das concepções de saúde relacionadas com a comunidade, com o espiritual e com o passado difere radicalmente da concepção modernista que separa essas distintas esferas. Esse entendimento permite à autora compreender os conflitos vividos pelo grupo de curadores e sacerdotes e sua importância na manutenção e recriação da vida social no sul de Moçambique sob o domínio colonial. Há também um detalhamento etnográfico das fontes e uma interpretação criativa que mantém o diálogo entre as duas disciplinas, História e Antropologia.

Ainda que o período abordado seja bastante longo, este enfoque nos permite compreender o sentido da trajetória do grupo e as formas pelas quais a lógica modernizante e colonial foi vivida, reproduzida pelo estado nacional e até reapropriada pelo grupo dos tinyanga. Conseguimos acompanhar as várias contradições e complexidades das relações dos grupos sociais com os poderes coloniais e pós-coloniais.

O termo nyanga, semelhante a outros como ngoma, nganga, encontrados em outras partes do centro e sul africanos, diz respeito a um complexo de funções, práticas e saberes que não necessariamente estão concentrados no mesmo sujeito. Curadores, sacerdotes, conhecedores das ervas, intermediárias de espíritos por meio 
da possessão pertencem, portanto, a um universo que ultrapassa os termos ocidentais, em geral depreciativos, de curandeiro e feiticeiro ou o termo em inglês médico-feiticeiro (witch doctor), indicando a cura como parte de um processo mais amplo de intervenção social. O caráter político das ações dos tinyanga é assim evidenciado e discutido em vários momentos do livro.

O termo "médico tradicional" acabou por ganhar força ao designar um título de prestígio e reconhecimento - "médico" - acompanhado do termo "tradicional", que marca, entretanto, a continuidade da perspectiva oposicional e hierárquica entre "tradicional” e "moderno" tão ao gosto do pensamento colonial. Mas a autora mantém o uso de termos locais (nyanga, tinyanga), chamando a atenção para o universo de significados e práticas que eles apontam, sem no entanto perder de vista a luta por reconhecimento através da categoria posteriormente consagrada de médico tradicional.

A autora apresenta um quadro complexo, explorando as violências, ambiguidades e fragilidades do poder colonial na sua ação de controle e repressão sobre os tinyanga. Ganha relevo na análise o lugar do gênero nos diferentes contextos pois essas disputas ressaltam o papel das mulheres, que ganham protagonismo na esteira das ações repressivas coloniais que penalizaram mais intensamente os homens. A autora dá uma atenção pontual, mas significativa, às ressonâncias e continuidades das práticas e saberes de cura africanos no Brasil, identificando termos e significados da região do sul da África que continuam a ser reconhecidos na tradição afro-brasileira. Esse olhar lançado não é um detalhe, pois indica o compartilhamento não apenas de uma origem ou passado, mas de formas de continuidade e reprodução dos saberes antigos em processos coloniais e de repressão, seja em Moçambique, seja nas Américas. Sobretudo, fala de uma produção de conhecimento sobre África que é inequivocamente produzida por uma percepção não somente brasileira, mas afro-brasileira. Esta percepção não é específica em decorrência de qualquer tipo de continuidade linear do universo africano no Brasil. Ele é específico porque interage, percebe e questiona os universos africanos a partir do deslocamento afro-diaspórico. Sem guardar 
qualquer ilusão de identidade prévia ou essencializada.

O livro trata inicialmente das formas de controle tentadas pelo governo colonial contra os tinyanga perseguições, processos, proibições e as estratégias concebidas por estes para continuar a desenvolver seu trabalho. Em seguida trata das leis coloniais de proibição do trabalho dos tinyanga e da análise dos processos-crime. Os processos revelam uma diversidade de abordagens coloniais e as tensões em torno das percepções sobre feitiçaria tanto do ponto de vista colonial como local. Ressalta também o papel dos tinyanga na reativação da memória do Império de Gaza e na reprodução de identidades de resistência. Depois aborda as políticas empreendidas pela colonização na área de saúde, a partir das reformas realizadas após o Estado Novo português nos anos 1930. Nesta parte assistimos o confronto entre as formas distintas de compreensão da saúde, doença e cura, bem como as formas de lidar com os dois sistemas, tanto pelas populações como por agentes de saúde do sistema colonial em especial os enfermeiros africanos. Ao final, discute-se o momento, após a independência, da política do Estado modernizante moçambicano frente aos tinyanga e o esforço destes pela criação de redes e associações regionais na luta pelo reconhecimento do seu trabalho.

No primeiro capítulo, "A interdição das atividades da(o) Nyanga e seus agentes” acompanhamos como as práticas repressivas aos curandeiros guardam relação com o controle do trabalho indígena. $\mathrm{O}$ trabalho de "curandeiro" podia ser considerado como vadiagem e ser punido com a perda dos recursos advindos dos atendimentos médicos, a prisão, o desterro e especialmente o trabalho forçado. A mão de obra gratuita era proveitosa num momento em que o trabalho forçado estava sendo crescentemente questionado pela comunidade internacional a Portugal, que se via pressionado a diminuir seu uso, o que só se realizaria com o final do Estatuto do Indigenato, em 1961.

Nota-se na documentação usada pela historiadora menor repressão às mulheres tinyanga e, quando era o caso, punições mais baixas. A preferência em punir os homens era vantajosa para destiná-los ao trabalho forçado e a tendência era manter 
as mulheres no trabalho agrícola, inclusive impedindo-as de migrar para a África do Sul. Essas ações produziram um resultado inesperado: o aumento do protagonismo feminino nas práticas de cura e assistência religiosa às populações locais. Embora elas tivessem mais restrições à circulação, eram menos importunadas. Jacimara Santana ressalta que as mulheres também eram mais propensas ao transe, abrindo uma importante discussão sobre o lugar da possessão na atuação político-religiosa no sul de Moçambique e a ação destas mulheres como mediadoras.

O transe remete ao passado no sul de Moçambique. Foi nessa região que emergiu o Estado de Gaza, no começo do século XIX, a partir da invasão pelos grupos nguni do território sobretudo tsonga e ndau. Nessa tradição, as mulheres que recebem espíritos são conhecidas por um título próprio, nyamussoro. Esses espíritos seriam estrangeiros, geralmente de antigos guerreiros nguni ou ndau que exigem casar com mulheres vivas para receberem os cuidados que não tiveram na altura de sua morte. Este fenômeno aponta para trocas culturais entre os ndaus, tsongas e ngunis, e indicam a importância das práticas religiosas na reatualização das relações sociais e políticas daquela região.

As fontes estudadas mostram que as acusações de feitiçaria recaíam de forma expressiva sobre as mulheres, consideradas perigosas por pertencerem a linhagens estrangeiras. Também tinham o poder de intermediação entre vivos e espíritos, conferindo a elas uma posição ambígua, entre proteger e agredir. $\mathrm{O}$ esforço interpretativo de Santana sobre o protagonismo dessas mulheres a faz entrar em diálogo com as feministas africanas que questionam a visão feminista ocidental, que assinala uma maior submissão das mulheres africanas em contextos patrilineares e virilocais. A pesquisadora relativiza esta sujeição apontando o papel religioso e mediador assumido pelas mulheres, que não estavam relegadas a papéis puramente domésticos e reprodutivos.

Atenção importante é dada ao lugar das missões cristãs, instituições centrais do domínio colonial e responsável pelo trabalho de deslegitimação dos tinyanga. A igreja presbiteriana, conhecida como missão suíça, foi, entretanto, mais bem sucedida que a 
católica na relação com a população daquela área, investindo desde cedo em estudar os tinyanga e suas atividades. Henri Junod, o mais importante etnólogo do período colonial naquela região era desta missão. Assim, a coexistência entre tinyanga, católicos, protestantes suíços e cristãos das novas igrejas africanas se apresentam no trabalho de Santana com riqueza de situações. As atitudes variaram entre animosidade, distanciamento, desconfiança, mas também casos de adesão, com o reconhecimento da eficácia do trabalho dos tinyanga por parte dos missionários.

São bem exploradas neste capítulo as contradições nas relações entre governo colonial e os tinyanga, na medida em que estes mantinham boa reputação e ascendência entre a população, as chefias e mesmo entre os brancos. A sobreposição das funções de chefe político e religioso, bem como a interdependência entre tinyanga e chefias locais, conferiam àqueles uma importância e um papel que não pôde ser facilmente descartado pelo regime colonial.

O capítulo 2, "Lei, costume e contestação ritual”, procura discutir o aparato legal que o regime português acionou para controlar e coibir a ação dos tinyanga. A autora aqui busca rebater o senso comum de uma suposta tolerância portuguesa aos costumes africanos, comparada a outras potências coloniais. Procurando desnaturalizar esta perspectiva, Jacimara Santana discute a distribuição das atribuições administrativas, jurídicas e políticas, como a criação do Código Indígena Local, tribunais, ordenamento territorial e outras medidas coloniais. Ela aponta como a ação civilizadora colonial portuguesa, orientada para políticas de assimilação e coerção para o trabalho, também produziu formas seletivas de acomodação e contemporização com vistas à diminuição de tensões e conflitos.

Não apenas processos administrativos, penais e relatórios coloniais encontrados nos arquivos, mas depoimentos obtidos em campo complementam e dão outras perspectivas e nuances interpretativas a esta discussão. Assim, podemos ver os casos de autorização para uma pequena parte dos tinyanga exercerem suas atividades, restringindo funções e mantendo-os sob vigilância, especialmente quanto a práticas percebidas como "feitiçaria”. 
A “feitiçaria” emerge como o ponto sensível do empreendimento civilizatório colonial. Ela é extensamente referida nas preocupações dos colonialistas. A pletora de práticas, ações, poderes e agentes passíveis de serem reduzidos ao termo ocidental de feitiçaria ou bruxaria, feiticeiro ou bruxo, indica o esforço classificatório colonial por fenômenos que escapam ao seu domínio.

Um aspecto notável do trabalho de Jacimara Santana é fazer-nos perceber a importância dos tinyanga como personagens fundamentais para a manutenção e recomposição dos laços sociais e culturais em um processo de desfazimento produzido pela colonização. A ascendência deste grupo não passou de modo algum desapercebida pelos poderes coloniais. "Os tinyanga ofereciam tratamento para os efeitos desestabilizadores causados pela dominação colonial” (p. 188). Ou seja, as práticas de medicina local não dizem respeito a formas de viver e compreender o mundo que paulatinamente desapareceriam sob a pressão colonial, elas se atualizaram e continuaram a fazer sentido como resposta a processos contínuos de crise, pondo em questão suposições que alocam a tradição em um passado fixo.

Neste capítulo, o trabalho se detém na discussão da presença e importância dos tinyanga desde o Império de Gaza, fazendo uso extensivo da rica documentação que a autora pôde acessar, bem como da bibliografia histórica e antropológica disponível. Apesar de por vezes fazer comentários críticos um pouco apressados sobre os trabalhos antropológicos, via de regra reduzindo-os a perspectivas meramente coloniais ou eurocêntricas, o que nem sempre foi o caso, Santana soube aproveitar bem esses textos e relacioná-los às fontes orais e escritas.

Acompanhando atentamente a produção antropológica que lê os movimentos religiosos como formas específicas de protesto anticolonial, a autora oferece terreno para observarmos a ação dos tinyanga, em especialdasmulheres, pela experiência do transe, na recomposição do social através da ressignificação do passado, ao reavivar a experiência do Império de Gaza na luta contra a invasão portuguesa no final do século XIX. Esta memória se reatualiza nos conflitos coloniais, através dos 
eventos de possessão espiritual de antigos guerreiros. Isto permitiu que a memória de resistência e luta vivida na guerra de Gaza contra Portugal se reativasse nos desejos e movimentos de resistência emergentes em meados do século XX.

O capítulo 3, "Conhecimentos africanos e ocidentais de saúde sob o regime colonial”, trata da oferta de serviços de saúde pelo regime português e as disputas e convergências entre as instituições e os saberes coloniais e africanos. A assistência à saúde, normalmente oferecida pelas missões e, no caso do sul de Moçambique, pela missão suíça, talvez seja, entre as instituições coloniais, o mais importante dispositivo assimilacionista. Não relacionados com a dimensão cultural e ideológica da educação, da imposição da língua e dos “costumes”, nos serviços de cura pela medicina científica são depositadas as maiores expectativas de adesão e transformação do universo indígena. Qual seja, o abandono das práticas "supersticiosas" e de "crenças" infundadas ao confrontarem-se com o escrutínio "transparente" da evidência científica.
Assim, pareceu surpreendente aos coloniais a persistente rejeição dos africanos ao tratamento de saúde ocidental. Jacimara Santana explora os diferentes papeis dos serviços coloniais de saúde. Estes contemplam não apenas o conhecimento e o controle das populações para uma oferta estável de mão de obra, como também a imposição do modelo cultural ocidental sobre saberes e práticas locais sistematicamente desqualificados. Impõe-se aí a legitimação da dominação colonial pela hegemonia e adesão culturais, numa disputa árdua para os colonizadores e missionários.

Concomitantemente à conversão de almas, através dos corpos nativos instaura-se também um conjunto de saberes - sanitários e etnológicos que ajudam a melhor conhecer as "raças dominadas”, suas condições de vida, doenças típicas, aspectos territoriais e climáticos que possam contribuir para uma atenção sistemática à saúde da população e seu controle, numa perspectiva higienista.

Observam-se políticas de controle, prevenção e identificação dos males a debilitar os africanos a partir de um conhecimento interessado. A causa da 
tuberculose é atribuída a condições climáticas - mas não às más condições de trabalho. Evitar o abuso de bebidas africanas - mas não do vinho português - passa a ser uma política chave entre as medidas de saúde coloniais. As ampanhas de vacinação foram outra pedra de toque da intervenção colonial no campo da saúde.

Entretanto, o fraco interesse dos africanos em buscar atendimento nos postos de saúde e persistirem nos tratamentos ministrados pelos tinyanga não pode ser explicado pela sabida precariedade dos serviços médicos coloniais. Ao longo do capítulo percebemos que a consistência do tratamento dos tinyanga está baseada na sua coerência com o modo de vida africano, no qual a saúde física está correlacionado a outros aspectos da vida. Os tinyanga continuaram a atender as expectativas da população do sul de Moçambique, com o agravamento das suas condições de vida pelo aprofundamento da exploração do trabalho.

Interessante aspecto é o lugar dos enfermeiros africanos como mediadores entre as ações médicas e sanitárias coloniais e as populações locais, sendo muitas vezes os únicos agentes de saúde atuantes entre os africanos, além dos tinyanga. Intermediários da colonização, eles exerceram um importante papel na legitimação da medicina ocidental frente às populações no cuidado de doenças que os tinyanga não sabiam como tratar. Mesmo assim, a relação entre estes dois grupos variou da intolerância dos enfermeiros frente aos tinyanga, advinda da incorporação do ideário assimilacionista, a casos de colaboração mútua, tendo em vista a legitimidade de ambos, posto que africanos, junto às comunidades.

$\mathrm{Na}$ prática, os africanos e muitas vezes os próprios brancos acionavam os dois sistemas, o serviço médico científico e os tinyanga. Mesmo com o crescente reconhecimento da eficácia da medicina ocidental, a procura aos tinyanga não cessou, ocorrendo a depender do tipo de doença e da interpretação sobre suas causas. Doenças e sintomas (físicos, psicológicos ou de condições de vida) eram entendidos como resultado de um desequilíbrio de forças sociais, rompimento de tabus ou atos de feitiçaria, oriundos portanto de uma relação desequilibrada entre 
os vivos, bem como entre estes e os antepassados.

Desta forma, concepções muito distintas de saúde ebem estar acabaram por atuar paralelamente, entretanto sob tensão, especialmente quando a ação dos tinyanga ia sendo percebida pelas autoridades coloniais como uma forma de resistência e contestação ao regime colonial. Resistência a campanhas de vacinação, intervenção sobre crises sociais decorrentes da exploração e da dominação, criação de objetos de proteção individual para trabalhadores em situação de risco vão ganhando novos sentidos no acirramento das relações coloniais.

O capítulo 4, "O retorno do grupo Nyanga ao cenário público”, se detém no período que vai da luta anticolonial até após a independência, quando das relações hostis sobre tinyanga por parte da Frelimo. O reconhecimento do grupo pelo Estado independente, após o final da guerra civil, culminando na criação da Ametramo em 1992, pertence a um período posterior, referido mas não trabalhado no livro.

Neste capítulo a autora aborda a intensa circulação dos tinyanga pelo território, ultrapassando frequentemente fronteiras coloniais, fazendo emergir redes, circulando prestígio e autoridade de alguns deles fora do território colonial português. Esta circulação de tinyanga para fora da colônia, bem como de pessoas em busca de tratamento que entravam no território português, era vista com desconfiança pelas autoridades portuguesas, um indício de organização translocal e propagação de ideias nacionalistas.

A circulação possibilitou a formação de associações transnacionais de tinyanga, abrangendo espaços como Moçambique, Zimbábue, África do Sul e Suazilândia. Estas associações possibilitaram o compartilhamento de conhecimento e práticas de cura em âmbito regional, como também reforçaram identidades nacionais e uma rede de apoios para a resistência anticolonial e a luta por reconhecimento frente aos governos dos Estados independentes.

Sendo assim, muitos tinyanga assumiram funções de articulação política. Encontramos aí um tipo de mobilização político-religiosa durante muito tempo interpretada como uma forma "pré-política" ou primitiva de resistência. Jacimara Santana mostra como essa mobilização foi percebida e tratada de diferentes formas pelos 
líderes nacionalistas modernos. Estes a entenderam ora como formas atrasadas e perigosas de mobilização, a serem combatidas, ora como formas populares e legítimas, que podiam conferir confiança às populações no combate ao colonialismo, devendo portanto ser estimuladas, ainda que de forma controlada.

Por fim, a postura de desconfiança do governo da Frelimo em relação aos tinyanga produziu ações fortemente repressivas, voltadas a romper práticas vistas como obscurantistas e a combater lideranças locais importantes fora da estrutura do partido. Já a Renamo assumiria o discurso oposto, de valorização das tradições locais e africanas, incorporando os tinyanga nos rituais de passagem dos seus guerreiros, que visavam garantir proteção mística e invulnerabilidade diante do inimigo.

Políticas internacionais de valorização dos saberes endógenos, capitaneadas pela Organização Mundial da Saúde desde os anos 1970, e o importante papel dos tinyanga na produção dos rituais de reintegração social após o fim da guerra civil, foram fatores relevantes para o reconhecimento desses sacerdotes por parte do Estado, embora não sem contradições. A coexistência de formas muito distintas de entendimento sobre corpo, saúde e equilíbrio social e cósmico resultou em diversos conflitos. A tentativa de classificação das funções dos tinyanga e a restrição da atividade do curador ao conhecimento de ervas são alguns dos exemplos.

Em suma, trata-se de um livro com enorme riqueza de temas, que acompanha a tenaz aventura de mulheres e homens que buscam persistir na recriação de seus modos de vida sob o domínio colonial e tentativas de epistemicídio. Nota-se o trabalho de visibilização da atuação de mulheres tinyanga, pouco ressaltadas na documentação escrita mas reveladas pelo sensível trabalho de história oral empreendido pela autora.

\section{Luena Nascimento Nunes Pereira (D)}

Universidade Federal Rural do Rio de Janeiro 